\title{
Revising the Faculty Manual: The Client Project in Your Backyard
}

\author{
Heather Lettner-Rust*
}

$06 / 20 / 2018^{\dagger}$

\begin{abstract}
This client project is a culminating assignment in an upperlevel professional writing course designed to help students understand the nature of audience-based writing in an unfamiliar writing context. The specific task is for students to revise a substantial section of the university Faculty Policies and Procedures Manual. Students researched their audience, analyzed samples of university manuals at other higher education institutions, exercised document design strategies, and practiced syntax revision during the project, ultimately presenting a sample of their work to faculty for feedback. Employing design workshop strategies, this assignment requires students to interview faculty in order to understand multiple users' experiences of the university Faculty Policies and Procedures Manual. In addition, an essential component for student learning in this course is reflection. This reflection is centered on the rhetorical situation of using and revising genres (Devitt, 2009 ) in the context of a professional environment (Clark, 2005; Kain \& Wardle, 2005) in order that students avoid perceiving the class as a march through memos, reports, and emails as static formats (Miller, 1984). This project engages students independently, as they are responsible for their own revisions of 30 pages, while class time is used collaboratively on learning new ways of viewing the document's potential and the genre's function.
\end{abstract}

\section{Reflective Description}

This assignment, from a course called Professional Writing Skills (English 470), is a client project that asks students to revise 30 pages of the university's Faculty Policies and Procedures Manual (FPPM) based on user-centered research and rhetorical principles. The assignment has evolved to its current iteration over a number of semesters and is

\footnotetext{
*English Department, Longwood University, lettnerrusthg@longwood.edu. Copyright 2018 Heather Lettner-Rust. This work is licensed under a Creative Commons Attribution-NonCommercial 4.0 International License (http://creativecommons.org/licenses/by-nc/4.0/).

${ }^{\dagger}$ Submitted, 08/25/2017; Accepted, 03/19/2018.
} 
suited to the needs of the students and the outcomes of the course. The assignment can be adapted to other courses and programs using the foundational rhetorical principles on which the course is based.

\section{The Course and its Rhetorical Foundations}

This course serves many masters. It is required for our Professional Writing concentrators. English majors must take either this course or another called Technical Writing. In addition, this course is required of majors in Communication Sciences and Disorders for professionalizing their writing prior to entry in the field of Speech Language Pathology or other communication therapies.

As such, this course helps students situate their understanding of future writing contexts by teaching professional writing as a rhetorical situation. I would argue most students need assistance in moving beyond the construct of a classroom writing assignment handout in order to see the more robust writing situation of a workplace environment. Any writer, even a distinguished academic writer, needs assistance embodying the role they must play as a writer at work (Anson, 2016). As Irene Clark (2005) describes, what often happens is:

[s]tudents glance at their writing assignments without identifying that they are being asked to play a particular disciplinary role because they do not recognize that assignment as a performanceoriented genre; nor do they understand how genres function in a disciplinary context. Genres ascribe to those involved distinct personae and social roles, depending on the recurring situation, but students who are novices to the discipline in which they are being asked to write are often unaware of what constitutes an appropriate persona. (para. 12)

In this case, students must read the assignment asking them to revise the university's FPPM beyond their role as student and now through the personae as editor and designer. Helping to situate them in that role, the requirement is that students will meet various university faculty who enact persona as instructors and colleagues, have discrete needs for the manual, and have many times been a writer and editor of the selected section the students are revising. This requirement helps lift the assignment beyond the page to the project as a genre revision that lives within a rich work-environment. Furthermore, the activities carefully meet many of the outcomes of the course simultaneously. For English 470: Professional Writing Skills, students are to:

- Analyze and produce writing genres commonly found in the professional world (e.g., business, gov., media);

- Create and/or revise professional documents that use plain English (clear, concise, and grammatically correct); 
- Conduct research to create content for a variety of professional documents (memos, letters, reports, etc.);

- Create and/or revise professional documents that use design - standard formats, layout, use of graphics, etc.;

- Practice oral communication skills to present content effectively (enhanced with multimedia tools);

- Participate productively in collaborative projects.

Thus, interviewing faculty as audience lifts the project off the assignment sheet and past most attempts to invoke or invent an audience.

One issue that arises in a professional writing course is the often-necessary use of an invoked rather than addressed audience (Ede \& Lunsford, 1984). Textbooks do as much as they can to deliver a complex situation; however, asking students to write a memo to a workplace they have not seen, or a boss they do not know, brings students back to a place of inventing the university (Bartholomae, 1985). Consequently, the audience imagined can undermine the strength of the students' writing as the exigence for the writing is also imagined. Interviewing faculty as users for a document that lives and breathes in faculty workspaces helps the students see an audience as complex, and the manual as a flexible genre responding to the needs of faculty concerns and behavior.

Another potential issue in professional writing courses is students' universalizing the genre into future workspaces. Amy Devitt's (2009) work within her own classroom moving students to "see genres as things, then as processes, and within larger contexts" (p. 348) is a useful practice. Students can more readily see this genre, the manual, as a thing because it is unfamiliar to them. We can take it apart, name the functions of certain sections, discuss the action required of the reader, and theorize about the writer(s)'and reader(s)' goals. Adding faculty visits to the classroom invites the discussion the genre as developed by a process and a perceived exigence within the ideological context of the university.

Achieving all three of Devitt's elements defining genre - as "things," "processes," and within "contexts" - is an iterative process that unfolds as a response to interviews, research, and discussions in class. In addition, the interviews and research are an intentional disruption students' default to reading the genre as an outsider and truncating the language (A. J. Devitt, Bawarshi, \& Reiff, 2003). What I do not want is for students in their future workplaces to see genre as a form to fill; rather, they should see genre as the fluid space designed to meet the needs of the situation (Miller, 1984). By asking students to revise a manual that exists in their university (albeit not for their use), the assignment urges students to sense the complexity of context.

Engaging students in a classroom interview with stakeholders of the manual allows them to pick up some of the varied complexities of hearing the verbals and reading the non-verbals of a live interview as research. Meeting the outcome of collaborative projects, these interviews are conducted as a team whose members may interpret the situation in multiple ways. Understanding the rhetorical situation of audience, context, message, 
and the writer's persona as a communicator enhances the students' experience with conceiving genres as flexible according to audience expectations, situational contexts, and a rhetor's interpretation of those elements.

Enter the FPPM. A class project was born.

\section{Project Evolution}

Previously, I had students find their own clients. Even with a requirement to find manageable projects and suitable clients, the assignment elicited a wide range of client needs and contexts which translated to differing levels of complexity for writing tasks. This inequity of writing tasks made the evaluation of students' writing projects and products difficult to judge with an acceptable level of equivalence. I did find that requiring an ending reflective component made evaluation a little more equitable.

In addition, this previous assignment design called for only a mid-progress conference and near-final stage presentations. Feedback given at these stages did not seem to influence the final product constructively. Their work continued to vary based on their novice ability to find a rich context in which to produce a deliverable.

The newer version of this assignment was adapted from another instructor teaching our Technical Writing course, Elizabeth Magill. She had students revise a government educational policy manual. Students we had in common enjoyed the project. I could appreciate the level of sentence revision students were doing on a project that was neither sexy nor topical to them. My adaptation to this assignment was that students needed a document they could discuss with its audience. As such, this current project of working with the FPPM could be used with any university document, so long as the user(s) can be interviewed. One document to consider might be a student university handbook. Students are easily gathered for interviews or usability tests. The student editors are much closer to the meaning of the text and could even be considered content-experts. My choice of the faculty manual was meant to remove them somewhat from the content, thus requiring students to reach for research. I wanted them to stretch to understand audience rather than take over in decisions of content change based on their experience. Ultimately, I thought that working with the faculty manual would more closely match their workplace context in terms of distance to the material.

One of the benefits of this whole class client project is that it requires the class to work with the same client (the faculty) and the same writing task (a specific section of the FPPM). Each semester, the next class works on the next 30 pages, ensuring that plagiarism from semester to semester is not an option and allowing us to actually complete the entire manual. Having the whole class work on the same 30 pages in one course allows the instructor to guide students' approach to the writing task at various stages of the project - from user-centered interviews as intensive and intentional research, to document design with useful headings and artful graphics, to micro-level sentence work. 


\section{Teaching and Learning Together}

Our first work is to examine the document. We take a look at it as a "thing" (A. Devitt, 2009). What does the cover say? What does it communicate? Why a table of contents? Flip the pages. How does the design of content work for a reader? Does the design communicate something unintended to the reader? Students begin to conceive of the praxis of poor design, redundant content, and the necessity for some legal language but also the necessity for cohesion and concision. During this initial discussion, I am able to underscore the relationship of improved readability and usability to the reader's memory. Rather than telling them these principles are important, I can connect the rhetorical principles of readability, usability, and memory to their opening observations of the manual and remind them that these principles guide their revision.

Next, we conduct a usability test on the manual in its current form with selected faculty invited to the class session. Prior to the course, I reach out to faculty across the campus to ensure diverse audiences, but I also ask the students for nominations. Faculty are more likely to respond when I say they have been nominated and will be interviewed by their nominee. I try to speak to the constraints on faculty time by assuring their commitment will require just two visits, with no preparation necessary, no materials to bring, and the interview will take place with a small team for 20 minutes of their time.

Testing what users find useable is a sticky question. In collaboration with student teams from previous semesters, I have developed a list of 5 questions, which each team uses every semester. The common questions mimic a quasi-experimental approach, allowing us to compare interviewees' responses by expertise, seniority, disciplinary ways of reading, and user's point of need longitudinally and within the semester. Here are the guidelines for these interviews:

Directions: Greet the interviewee, thank them for their time, estimate that this will just take about 15 minutes. Introduce yourself, your team and explain the purpose of the interview: "to gather information about your experience with the FPPM and to help us understand the institutional context for the manual."

1. What is your title, rank, and what committees are you on?

2. Estimate how many times you have consulted the FPPM during this academic year.

3. For what purposes do you consult the FPPM?

4. Do you use the manual online (either from the website or by pdf) OR do you use it in paper?

5. What do you think of the writing and organization?

Say this: "These questions will ask you specifically about your use of the manual."

1. How do you navigate the information in your manual? Show us how you 
find a section you typically reference. And could you talk through what you're doing and thinking.

2. Is there a format or template for the sections of the manual that you know of? If not, what are your expectations as you open the manual to find information?

3. Take a look at this copy of page - Using a highlighter, please note any words in - that you recognize to have meaningful connotations associated with the university. Could you then explain the meaning of these words to university faculty and administration?

4. This next question is about layout. Look at page —, - and describe how the information is laid out. What are your eyes drawn to first? What do you see next?

Our last question: Is there anything you'd like to add about the manual that we have not asked?

The last question, in particular, typically produces useful information.

As the class debriefs, we can discuss: How does a dean read the manual versus a first-year tenure-track professor versus an adjunct? What does a user need to know according to their job? Those jobs posit different levels of urgency connected to dayto-day responsibilities. To a certain extent, the students are not able to conceive of the scope of the dean's job. As an associate professor, even I do not have a complete conception. I assure them that I will not penalize them for revising a section in error due to their novice status. I am looking for a researched justification of their changes in a reflective letter. That research involves citing from the interview, online research with other university manuals, the plain language guidelines, and material they have read about our institutional context.

Students can see the complexity of revising the manual in the variety of answers we get from interviewees. I question the students about what they can conclude from the variety of responses and am most impressed with the students' level of engagement during and after the in-class faculty interviews. Our whole-class discussion of their findings has even the quietest students offering conclusions because I encourage the smallest observation. In fact, recently one of my silent students spoke with gusto about her faculty member's enthusiasm about the manual, noting that her interviewee does not want anything changed in the manual. I urged them to listen to the variety of users' experiences to hear the responses that confirm and resist our need to change the manual. It is during discussions such as these, after I have placed them in situ and we debrief, that I find students to be speaking the very words I could be uttering in a lecture. They begin to own the research and the drive for the project.

Another point of engagement for them in the interview is to use a team-based approach. The course is writing-intensive as well as speaking-intensive, requiring instructor-guided practice in both writing and speaking. This speaking engagement allows students - in teams of 3-4 at the most - to set up the process for a team-driven interview. It is a more 
fluid process of presentation requiring team members to take roles but also jump in to fill gaps or review questions during the interview. I ask them to assign roles -interviewer, notetaker (two if it is a group of four), and troubleshooter - to extend any questions or offer new questions for any pieces of information they want to pursue. I explain it as a fluid process, something of a semi-structured interview we use in composition research.

After that research step, they are to interview a faculty member individually and upload their notes to our course website for all to read. These notes become the basis of their final letter addressed to the provost justifying the changes they made in the FPPM. The letter is not actually sent to the provost because she did not initiate the project (a committee is typically in charge of revisions), and her office could not and should not have to handle 18-36 letters. This is my way of asking for student reflection as justification while practicing a formal workplace letter genre. Again, this may seem as though they are inventing an audience, and they are to an extent. But if I had them direct it a committee, the audience would be an even greater invocation.

The next steps are mini-lessons I lead during their ongoing, self-regulated revision of the 30 pages. Any types of lessons could be inserted here based on the type of document you choose. I introduce them to Plain Language Principles by bringing up the webpage of the federal government's webpage on guidelines in class. The Plain Language effort was started in the 1990s to eliminate obtuse and unnecessarily dense language from federal documents. The principles are explained in a user-friendly hyperlinked outline under headings such as: write for your audience, organize your information, and design for reading. I point out that these very lessons are included in their textbook, lifting the credibility of both sources. The use of the Plain Language website also sanctions an outside resource they might use in the future, locating credible materials beyond the classroom.

As we discuss various ways to revise the manual - for example breaking up large chunks of text with subheadings using specific pages of their assigned section-they again show a level of engagement because this is a sampling of the very work they are doing on their own time. We can discuss the effect of using questions, statements, or topics for headings, the need for parallel structure, and the use of typography for levels of importance. Sometimes, students are engaged simply because they know this helps them complete a page with assistance. More frequently, students respond because they have revised a passage differently, and we can discuss the pros and cons of various designs or heading choices. Once they see the pragmatic consequences for certain design or syntactic choices, we can circle back to the discussion that genres are not a static container. Our choices reflect, at once, an Aristotelian sense of persuasion being "the faculty of observing the available means of persuasion" $(2006$, p. 7$)$ and also that guidelines, are just that, guidelines. They are a heuristic applied within an institutional context rather than a set of rules determining style and language choices. Each of their choices can deliver different meanings to different audiences within varied contexts. 


\section{Final Thoughts}

In the end, I am gratified that students have embraced this project in ways that students writing teacher-as-audience assignments have not. More than one student, and not always the Professional Writing minors, have told me that they liked doing this kind of editing work. More than that, the students tell me that they are visually revising many signs, texts, and other graphics because they cannot look at documents in the same way. They are also revising everyday emails, they tell me. To disrupt their habituated writing is the best pedagogical goal I can think of.

The next step towards improving this assignment will be to incorporate more metacognitive reflection, for students to be more aware of what they bring forward from writing for other course assignments and other classes. Teaching for transfer research (Yancey, Robertson, \& Taczak, 2014) suggests that instructors should help students recognize opportunities to do the lifting and modifying of skills from prior writing experiences. This assistance helps students operationalize those skills to the next writing context. Adler-Kassner and Wardle (2015) suggest we center our writing courses in threshold concepts such as rhetorical situation, genre, audience, and reflection that will concretely give students the language to describe the work of writing. When my rotation for the course comes around again, I will work on this explicit naming approach next. While my classes over many semesters completed revision of the entire 352-page 2014-5 manual, the faculty have been revising it too. In a few years, we may have a whole new document to march through again.

\section{The Assignment: Professional Writing Client Project Overview English 470: Professional Writing Skills, Spring 2017}

See the Supplementary Files for this article at thepromptjournal.com for a PDF facsimile of the original formatting of this assignment.

Originally opened in 1839 as the Farmville Female Seminary Association, the institution was chartered as a Female College in 1860 with 7 faculty covering Mathematics and English, French and English Branches, Piano and Guitar, Drawing and Painting, and Music and Organ. Longwood University in 2017 is now a liberal arts university with a faculty of 288 spanning the colleges of arts, sciences, business, health and human services, in addition to graduate programs and pre-professional tracks such as teaching, athletic training, and nursing. As the school has grown, so have the procedures and policies.

We are taking the opportunity to re-design and revise 30+ pages of the 2014-2015 Faculty Procedures and Policy Manual. Your guiding principles are to polish the document for 1) readability, 2) fluency, and 3) memory. 


\section{Steps for the Project}

\section{Research}

In class, we will discuss samples of other manuals in higher education to review the genre for its language, formatting, and purpose. You should then search independently for samples of university faculty manuals that can shape your ideas.

In small groups, you will interview faculty in order to understand users' experiences with the FPPM. You will also read (in Canvas under Modules) interviews with users (a dean and a few professors) of this manual for their practices and perspectives on the contents.

\section{Drafting and Design}

This work involves removing redundancies, cutting long sentences, and re-ordering paragraphs for better organization of ideas. You should not change meaning. You should enhance or bring forward meaning. The Federal Plain Language Guidelines [www.plainlanguage.gov] will be our strongest guide for understanding how to write clearly for an audience.

You will also employ design principles from the Non-Designer's Design Book to make the white space and text space more readable and memorable.

While you work on the manual, we will also have some grammar, mechanics, and editing lessons to sharpen the readability of the sentences.

\section{Check-in with clients}

We will bring back faculty to have them review the work your team would like to submit. Selecting just a representative page or two, you will show the faculty member what you have done and why to get their feedback.

\section{What's due in the end}

Each student will turn in two pdfs: a letter to the Provost as a progress report and your final draft of the selected section of the FPPM. Save the pdf as "Your last name first initial [name of document].pdf"

The final draft will be a clean draft of your revised FPPM with nothing highlighted.

The progress report letter (follow the sample in Writing that Works p. 355) will have with 3 subheadings. Your audience will be Provost Joan Neff, Vice President of Academic Affairs of the university.

The first subheading will be Content Changes in which you justify 3 of your more significant content changes. Quote from the FPPM to illustrate the sample changes. 
The second subheading will be Design Changes in which you justify 3 of your more significant design choices. Quote from the FPPM to illustrate a sample change.

All 6 changes should be explained according to audience, purpose, and/or context by citing the sections/ pages of the FPPM.

The final subheading will be Recommendations in which you explain whether this work should continue or not for the rest of the manual. You may also forward good suggestions you heard during interviews or considered on your own.

Note in your letter the reduction of word count in your version.

\section{References}

Adler-Kassner, L., \& Wardle, E. (2015). Naming what we know: Threshold concepts of writing studies. Logan, UT: Utah State University Press.

Anson, C. (2016). The Pop Warner chronicles: A case study in contextual adaptation and the transfer of writing ability. College Composition and Communication, 67(4), 518-549.

Aristotle. (2006). On rhetoric: A theory of civic discourse. (G. A. Kennedy, Trans.) (2nd ed.). Oxford: Oxford University Press.

Bartholomae, D. (1985). Inventing the university. In M. Rose (Ed.), When a writer can't write: Studies in writer's block and other composing-process problems. perspectives in writing research series (pp. 134-165). The Guilford Press.

Clark, I. (2005). A genre approach to writing assignments. Composition Forum, 14(2).

Devitt, A. (2009). Teaching critical genre awareness. In C. Bazerman, A. Bonini, \& D. Figueiredo (Eds.), Genre in a changing world (pp. 337-351). West Lafayette, IN: Parlor Press.

Devitt, A. J., Bawarshi, A., \& Reiff, M. J. (2003). Materiality and genre in the study of discourse communities. College English, 65(5), 541-558.

Ede, L., \& Lunsford, A. (1984). Audience addressed/audience invoked: The role of audience in composition theory and pedagogy. College Composition and Communication, $35(2), 155-171$.

Miller, C. R. (1984). Genres as social action. Quarterly Journal of Speech, 70(2), 151-167.

Yancey, K., Robertson, L., \& Taczak, K. (2014). Writing across contexts: Transfer, composition, and sites of writing (1 edition). Logan: Utah State University Press. 